\title{
Sin suerte pero guerrero hasta la muerte- Educación, pobreza y exclusión en la vida de José Medina. Granada: Octaedro. Ignacio Calderón Almendras (2015)
}

\author{
Candela Jiménez de Reyna \\ Estudiante de Ciencias de la Educación Primaria \\ Universidad de Cádiz \\ candelajimenezdereyna@gmail.com
}

Ignacio Calderón Almendras realiza en este libro una obra autobiográfica, dividida por capítulos, centrada en la vida de José Medina, un chaval cuya trayectoria ha sido una vida difícil basada en la exclusión social, la desigualdad y los problemas. El entorno que le ha rodeado a lo largo de su vida no ha ayudado en nada a mejorar su situación. Su vida ha estado marcada por idas y venidas de alcohol, desahucios, drogas... La sociedad ha oprimido a un joven con sueños e ilusiones, que como a él y otras muchas personas, no se le ha concedido una oportunidad. El autor quiere mostrar con esta obra un claro ejemplo de superación y de lucha constante que ayuda a concienciar de los problemas de nuestra sociedad actual, de muchas personas que tratan de continuar hacia delante.

De esta forma el autor se centra en un análisis sociológico y psicológico del sujeto, pero manteniendo en todo momento el carácter autobiográfico de la obra. Se aprecia por tanto el pasado complicado que envuelve la historia de este sujeto, la pérdida de su hermana en un incendio, la adicción de su padre al alcohol, los constantes cambios de ciudades, la precariedad de sus condiciones de vida... El autor apenas interviene en el relato de la obra, más que con simples aclaraciones y reflexiones.

De esta forma José pasa a convertirse en el eje central dando testimonio de todos los sucesos de su vida y de sus pensamientos en primera persona, defendiendo que no ha querido causar problemas en la sociedad, sino que ha sido ella la que no lo ha aceptado. Ha estado en numerosos colegios y defiende que en ninguno se ha sentido cómodo y respaldado, puesto que la escuela nunca le llamó la atención y él únicamente quería divertirse.

Dentro de la autobiografía se encuentra el testimonio de su madre, una persona con una vida difícil que ha pretendido darle lo mejor a sus hijos. Defiende la buena fe de su hijo, lo define como una persona inquieta pero muy inteligente, que dio un giro a su vida el día que logró salvar a toda su familia del incendio de su casa menos a su hermana, y eso lo cambió por completo.

Siempre ha vivido en barrios desfavorecidos contando con pocas ayudas, eso no ayudó a su integración social puesto que su familia es de raza gitana. Narra cómo se divertía al tener tantos primos, y que no necesitaba mucho para ser feliz. Pero a medida que fue creciendo las influencias le jugaron una mala pasada y fue cuando comenzó a escaparse de casa, a robar, su adicción a las drogas... 
Además del fallecimiento de su hermana, cabe destacar la naturalidad con la que habla del asesinato que se produjo a manos de su padre, así como de su etapa en la cárcel. Hace reflexionar de manera que se comprende como las personas pueden vivir con naturalidad situaciones que por norma general no lo son, pero al vivir en situaciones de este tipo de excepción los niños aprenden de lo que observan y lo consideran correcto.

A día de hoy el padre está en libertad, y en cierta medida lo admira, puesto que lo considera una persona que ha sabido darse su lugar, trabajadora y capaz de sacar a una familia adelante.

Nunca le han prestado una atención adecuada, ya que los profesores que ha tenido se han limitado a castigos y discursos, pero realmente nadie se preocupó por él. Las personas necesitan desde la infancia sentirse respaldadas, motivadas y con unas garantías, que en este caso no se produjeron. Aunque hubo una excepción cuando era muy pequeño, una profesora se ofreció a darle clases de manera individual en la escuela. De esta forma no tendría conflictos con los otros compañeros, pero no duró mucho tiempo según cuenta su madre agradecida por la dedicación empleada de manera especial a su hijo.

No le gustan las normas y es muy orgulloso, una combinación que no le ha ayudado, pero sin embargo las personas que lo conocen le tienen un afecto especial y lo definen como una gran persona atenta y trabajadora.

Todos los conocimientos que tiene se los debe, según él, al esfuerzo y a la paciencia de su madre que tarde tras tarde lo obligaba a que estudiara y le enseñaba todo lo que podía.

Repitió varios cursos, tanto en la educación primaria como en la secundaria hasta que finalmente pudo dejarlo, por lo que no cuenta ni con el título de la ESO. Eso le impide en muchas ocasiones acceder a un trabajo, que reconoce que es algo esencial pero no le interesan los estudios. Como muchos otros jóvenes que dejan sus estudios por aburrimiento y dan lugar al fracaso escolar, que ya debería de haber desaparecido.

Es muy bueno en el manejo de las manos, construyó él sólo una radio, sin necesidad de que alguien se lo enseñara o le explicara las piezas. Pero actualmente parece que si no se estudia una carrera universitaria no sirves para nada, es una de las causas de desigualdad de la sociedad actual.

Su madre se dedicaba a limpiar casas por lo que no podía centrarse en la educación de sus hijos exclusivamente; narra que apenas contó con el apoyo de los profesores que simplemente lo dejaron caer en el olvido.

José Medina es una persona diferente a la que no le han dado una oportunidad. Denomina a la escuela como algo aburrido, con asignaturas sin sentido y profesores sin rostro.

Este libro permite a sus lectores sensibilizarse con una experiencia real de una persona real. De esta forma da la posibilidad de ver con claridad la exclusión social y la opresión 
que sigue existiendo hoy en día en la sociedad. Defiende la necesidad de cambio, de acabar con el fracaso escolar y las injusticias sociales, de promoverlo y de defender los ideales en los que se debe fundamentar una sociedad, como la igualdad, el respeto y el progreso. Además el lenguaje cotidiano en el que se encuentra narrado dicho libro, hace más accesible su testimonio a todas las personas de cualquier rama de la educación.

Con el libro, se podría plantear la cuestión si la lectura ha ayudado siempre en el aprendizaje de circunstancias a las nuevas generaciones, hoy día que estas generaciones no se han logrado enganchar a la lectura, ¿cómo aprenderán a través de la imagen de la vida de otros reflejada en los libros? ¿Serán los nuevos medios tecnológicos suficientes para plantear retos y virtudes que puedan emular los más jóvenes?

¿Realmente la sociedad está cambiando o simplemente trata de aparentarlo? Se debe luchar por las personas y por su integración real en la sociedad, como dijo José Medina Sin suerte, pero guerrero hasta la muerte.

Cabe destacar para concluir que la sociedad actual debe llevar a cabo un cambio que permita a todas las personas sentirse integradas y formar parte de ella. En este ámbito los profesores desempeñan un papel importante, deben concienciarse de la importancia de la inclusión de todos los alumnos dentro de las aulas, desarrollando sus capacidades de la manera más óptima sin que eso signifique excluir a nadie. La sociedad debe ser consciente de la importancia de cada miembro que la integra, y que además el concepto de sociedad debe innovar, crecer y avanzar a la vez que lo hacen las personas. No puede quedarse estancada en el pasado, sino todo lo contrario avanzar y progresar, puesto que solo de esta manera se podrá llegar a alcanzar una sociedad justa e igualitaria basada en los valores. Dónde la libertad de poder ser lo que somos quede reflejada en la historia. ¿Es preferible excluir a toda aquella persona que sea diferente al resto e ir creando clones o crear una sociedad divergente?

\section{Referencias Bibliográficas}

Calderón Almendras, I. (2015). Sin suerte pero guerrero hasta muerte- educación, pobreza y exclusión en la vida de José Medina, Granada: Octaedro. 